\title{
Empirical Modeling for the Spot Price of Gold Based on Influencing Factors
}

\author{
Weihe Wang ${ }^{1}$, Weixuan Xia ${ }^{2}$ \\ *This paper is based on the first author's graduation thesis. \\ ${ }^{1}$ Guiyang Sasseur Business Management Co. Ltd., China. \\ ${ }^{2}$ Master of Science in Mathematical Finance, Boston University Questrom School of Business. \\ Correspondence: Weixuan Xia, Boston University Questrom School of Business, 595 Commonwealth Ave, Boston, MA, \\ 02215 , USA.
}

Received: February 17, 2017

Accepted: April 11, 2017

Available online: April 18, 2017

doi:10.11114/aef.v4i3.2295

URL: https://doi.org/10.11114/aef.v4i3.2295

\begin{abstract}
In light of the special roles of the price of gold on the technological and economic development as well as social aspects of human society, it is of great importance and necessity to develop a series of statistical models that, based on sound reflection of the current structure of the gold market, are able to provide valuable references for trends of the gold price. In fact, the gold price is influenced by a variety of economic factors. For forecasting purposes, it is useful to study the shortand long-run effect of direct and indirect economic factors towards the supply and demand of gold and thus the spot price of gold. To this point, this paper focuses on analyzing the individual and mutual impact of influencing factors on the gold price and, simultaneously, providing a short-term forecast of the price of gold based on the relationships with other major macroeconomic variables. While these relationships are modeled with multiple regression, forecasts of individual factors are obtained under multivariate time series models. The forecasting results are found to be accurate in a relative sense, confirming the significant impact of the factors chosen while indicating the validity of the modeling idea applied.
\end{abstract}

Keywords: gold price, economic factors, supply and demand, forecasts, multiple regression, time series

\section{Introduction}

Gold is a particular kind of commodity combining commodity functions with monetary functions, and is among the metals that were first discovered and used by human beings. Since ancient times, gold has been collected as a symbol of wealth and identity. Meanwhile, it has played a role of currencies mainly due to its stable physical characteristics and unique intrinsic value. Over the recent years, as factors including inflation were leading to the declining of currency values during economic turmoil, gold has come into play as a wall against risks and a storage of value. People prefer to hold gold in place of currencies, and the increase of demand for gold is also driving up gold prices. During the decade following 2001, with a sharp rise, the spot price of gold has more than quadrupled. The gold price is playing an increasingly important economic role in society.

Since it took place in 2007, the U.S. subprime crisis gradually evolved into a global financial crisis. Then, the value of the U.S. dollar (USD, \$) plummeted and investment products priced with dollar depreciated rapidly. On the other hand, investing in stocks and futures was highly risky, so people tended to hold commodities with lower volatility, such as gold. According to the data analysis conducted by the World Gold Council, the spot price of gold has been continuously increasing from the beginning of 2000. In particular, gold prices rose from \$650/oz in Jun 2007 to $\$ 970 / \mathrm{oz}$ in Feb 2008, with a nearly $50 \%$ increase, which drew the attention of many investors. In 2012, the U.S., Japan and other developed countries adopted expansionary monetary policies, resulting in a new height in the gold price at $\$ 1,776 / \mathrm{oz}$ in September of the year.

Over the recent years, gold has made it a focus of governments and investors. The U.S. $4^{\text {th }}$ round of Quantitative Easing (QE4) has infused huge amounts of USD into various markets, leading to a decline in dollar value. Also, during the economic recession of the Eurozone, European countries' economic growth has fallen below expectation. Moreover, with the turbulent political scene in the Middle East, the rise in oil price has indirectly placed new inflationary pressure on the international level. 
Based on the important role of gold in current society, quite a few studies have so far been conducted to analyze the impact on the spot price of gold from various macroeconomic factors. Smith (2001) analyzed the monthly data ranging from 1991 to 2001 and implied that stock indices have a significant relationship with gold prices, which was proven to be negative; further analyses indicated that other similar financial products also place a negative impact on the gold price and that gold can be an indispensable asset in investment portfolios. On the other hand, Pulvermacher (2004), by studying gold and stocks in American and English markets, found that during the three decades from 1973 to 2003, despite a clear negative relationship between the gold price and stock indices, their returns fail to reveal a significant correlation. In Gokmenoglu and Fazlollahi (2015), by volatility analysis, it is also confirmed that significant mutual impact exists between the gold price and stock indices. Besides, Ranson (2005) and Ranson and Wainwright (2005) indicated that current gold price can effectively reflect the expectation of upcoming inflation, because increases in gold price usually occur prior to inflation; based on this view, gold can be added to investment portfolios as a tool against expected inflation and that diversifies risks. Later, Levine and Wright (2006) studied the determinants of short- and long-term gold price, and concluded that gold can be an effective risk-avoiding tool against inflation in that gold price is positively related to the U.S. price level, and even if deviations occur in between, the relationship reappears with the passage of time, but a clear relationship was not found between gold price, inflation and income level. Furthermore, through analyses on the gold price and exchange rates data from 1982 to 1990 using methods of error forecasting, Sjaastad and Scacciavillani (1996) concluded that since the Bretton Woods System collapsed in 1971, real exchange rates among currencies have been the main cause of fluctuating gold price, whereas the impact of USD exchange rates volatility is but trivial, while it is the fluctuations in European currency exchange rates that significantly influence the trend of gold price; Sjaastad (2008) later restudied the relationship between gold price and exchange rates with updated data ranging from 1991 to 2004, only to obtain the exactly opposite results, as USD exchange rates were found to be the primary influencing factor while the Eurozone rates' impact ceased to be significant. Meanwhile, Adrangi et al (2003) proved that the gold price is positively related to inflation rates. He showed that within multiple economic cycles, the reaction of gold price to inflation is similar to other bulk commodities - they tend to rise when inflation occurs, despite that the initial increment in gold price is usually fairly limited; as inflation increases, however, gold price starts to go up at a speed far higher than other commodities.

In connection with this, this paper seeks to analyze the supply-demand factors influencing the gold price and, more importantly, find the implicit relationships between gold price and other significant price and index factors. Progressive expatiation will be provided via qualitative analysis, and quantitative analysis will be conducted to see whether these indirect factors are reliable predictors of the gold price. With respect to time, the quantitative analysis is based on 3-year daily data, which are thought to well reflect current situations and thus give greater guiding significance in practice.

The rest of the paper is organized as follows. In Section 2, qualitative analysis is conducted to discuss current gold supply and demand, as well as select and study several indirect factors influencing the spot price of gold, including oil price, stock index, USD index, risk-free interest rate, and contemporary inflation rate. In section 3 , quantitative analysis is provided as we test the relationships between gold price and each of the factors selected, in order to obtain a price trend forecast in the short run. In detail, a multiple linear regression model is first established to represent the potential relationships; then, for each influencing factor, a time-series sub-model is created to forecast its short-term trend; finally, the factors' forecasts are brought into the regression equation to obtain the contemporary forecasts of the gold price. In the end, Section 4 draws some crucial conclusions via discussion and comes up with several recommendations for future research.

\section{Qualitative Analysis}

Gold ore is the primary source of gold supply at present. Nearly $80 \%$ of the global gold production comes from the U.S., Australia, and China, yet over-exploitation of gold has impeded the recent years' general gold supply, since gold resources are non-renewable. In this connection, it has been a popular work to discuss the factors that largely influence gold supply, which can be divided into the following four categories.

\subsection{Factors Influencing Gold Supply}

\section{- Gold Mine Production}

The world's natural gold reserves, though unable to be renewed, are far from scarce. Thus, gold mining has been the uppermost means of gold production. Evidence to date indicates that up till the beginning of 2012, more than 140 kilotons of natural gold had been mined by humans, while nearly 6 billion tons of gold was still estimated to be scattered on the earth's surface. The global top 5 gold producers in 2014 were China with 465.7 tons, Russia with 272 tons, Australia with 269.7 tons, the U.S. with 200.4 tons, and Peru with 169.3 tons, in proper order. It is worth mentioning that China has made itself the leading gold producer in the world since 2007, and its gold production reached a remarkable number of 460 tons in 2014 after continuous increases, when Russia also outperformed Australia and took the second place upon a year-on-year increase of $9 \%$. 
However, resulting from the restrictions of its industry features and the relatively long investment horizon, the growth rate of gold reserves has been decelerating in general. This is because the process of gold exploration is considerably time-consuming, typically taking an average time period of 8 years to complete. An inevitable result is a "deferred" direct relationship between the gold price and gold production, i.e., gold price can be insensitive to mining. Hence, gold mining is not considered as a main cause of changes in the gold price, which do not take a long time, but there should logically be a weak positive relationship in between.

Seen from Figure 2.1, the world gold mine production (in metric tons, similarly hereinafter) has been climbing to new heights from 2009 to 2014. An explanation according to market research is that gold miners had been signing huge amounts of contracts during 2009 and 2010 to create liabilities for future production.

\section{- Recycled Gold}

Gold recycling, which contributes to around one fifth of aggregate gold supply, is another important source of production. The World Gold Council, as in the report jointly produced with Hewitt et al (2015), defines recycled gold as gold sold for cash by consumers or other supply-chain players, such as jewelry manufacturers that sell old stock.

Generally speaking, there exists a positive relationship between the gold price and the supply of recycled gold. Compared to other types of gold supply, recycled gold usually has supply that is relatively more sensitive to fluctuations in gold prices. Suppliers are considerably prone to increasing recycled gold supply when the gold price is rising, while decreasing it when the price is falling, making it very elastic. In fact, changes in the price of gold are in turn considered the biggest factor influencing recycled gold supply. Besides, changes in economic situations can also largely affect gold recycling. During good times, people are more willing to make high-risk investments through financial instruments like stocks and funds, when the amount of recycled gold correspondingly shrank. On the other hand, in an economic recession, gold appears to be more attractive along with higher liquidity to raise cash, which more or less increases recycled gold supply as well, thus lifting gold price.

Figure 2.1 indicates that the supply of recycled gold, upon a slight decline from 2009 to 2012, has dropped sharply since 2013, which led to the level of 1,121.7 tons in 2014. The underlying reason is that people with an expectation that gold price will fall are understandably callous about reselling their old jewelry or other gold-containing products, so that during 2013 and 2014, when gold price actually fell, it should not be surprising to witness a 2 -year decrease of $31 \%$ in recycled gold.

\section{- Central Bank Gold Sales}

Another main source of gold supply is the net gold sold by central banks. Just on May 19, 2014, the central banks of the eighteen member countries of the Eurozone, the European Central Bank, and Switzerland and Sweden's central banks announced to sign the fourth round of the Central Bank Gold Agreement. This agreement's debut was in 1999, when central banks' underselling gold was believed to be responsible for the crash of gold price to \$240/oz. Hence eleven European countries signed an agreement stating that within the upcoming five years, with signatory countries able to undersell gold up to 400 tons per year. In March 2004, the second round was signed, with the adjustment that gold sales should not exceed 500 tons per year. On Sept 27, 2009, the third round was subsequently signed, which reset the upper limit to 400 tons. In this newest round of the agreement, this limit remained at the annual level of 400 tons.

In Figure 2.1, European annual total gold sales are given in comparison with the gold price. Since the year of 2009, central bank sales have kept decreasing year by year, as they feel it is necessary to increase gold reserves on the purpose of hedging risks under unstable economic situations. This also implies a negative relationship between the gold price and central bank gold sales.

\section{- Producer Net Hedging}

Producer net hedging refers to the change in the physical market impact of mining companies' gold forward sales, loans, and option positions, according to the official definition posted by the World Gold Council. This can be created when the producers, upon anticipating a decline in the gold price, submit gold production plans to banks and lease gold, sell the gold at high prices in the markets, and finally pay off the lease while benefiting from the price spread. Comprehensibly, negative market expectations of gold price usually prompt the emergence of these transactions, and as a result of an excessive supply relative to demand, gold price can continue to fall. On the contrary, when the gold price abnormally rises up somehow, producers are automatically worse off.

Throughout the past six years, producer net sales remained at a relatively low level, despite a net purchase of 108.4 tons in 2010, as is shown in Figure 2.1, where it is difficult to observe a clear trend during this period. However, in the long run, producer hedging should have a direct impact on the gold price. Imagine a situation when the world economy is unstable, and USD borrowing rates and USD index are correspondingly decreasing, but gold borrowing rates are not. Producers' hedging profit will be curtailed relative to other investment choices, and so, there will be less net hedging. 


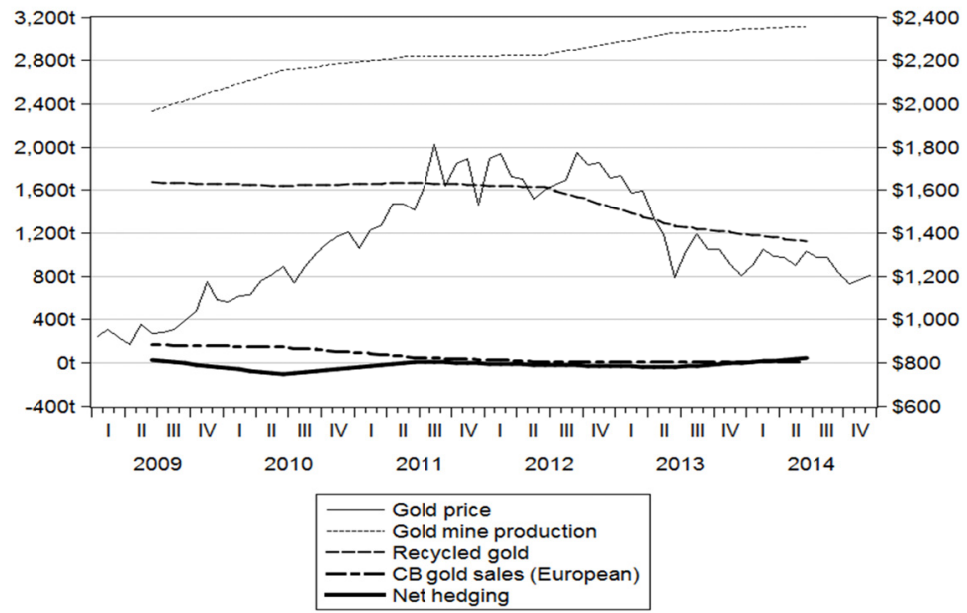

Figure 2.1. Gold price versus supply factors

\subsection{Factors Influencing Gold Demand}

\subsubsection{Explicit and Direct Factors}

According to the statistics released by the World Gold Council, global gold demand was 4,212.4 tons in 2014, among which jewelry took the first place, with 2,457.2 tons, gold bars and coins came in the second place, with 1,004.4 tons, followed by demand for investment in gold, with 820.6 tons, and official purchases, with 588 tons.

\section{- Jewelry Demand}

Based on the 2014 gold demand structure, jewelry demand accounted for $58 \%$ of the gold market, despite a $4 \%$ year-on-year decrease. Currently, the primary demanders are still the Asian countries that possess the customs of storing gold. These traditional consumption countries of gold include India, China, Turkey, etc. India, particularly, witnessed an $8 \%$ increase in 2013, which led to a demand of 662 tons in 2014, creating the best performance since 1995 . In these countries of gold consumption, gold jewelry is fairly income-elastic, as its demand is closely related to consumers' income levels. When people's income rises, their demand for gold tends to increase, and an attendant rise in consumers' purchasing power is prone to increasing gold jewelry demand. Moreover, the influence of gold jewelry demand on the price of gold is seasonally large. It is deemed auspicious to purchase gold during particular traditional festivals like the Spring Festival in China and Christmas in Western countries. At these key events, gold demand tends to increase, and is especially large in the first and fourth quarters of years.

According to Figure 2.2.1, gold jewelry demand (in metric tons, similarly hereinafter) was continuously increasing in 2009 and 2010, and became volatile afterwards, as indicated by a sharp increase in 2013 and a subsequent fall in 2014. In spite of the difficulty in confirming a clear relationship, jewelry demand should place a negative impact on gold price in the long run, for consumers' interests in pursuing identity and luxury can be significantly shrunk by the high cost of gold.

\section{- Technology Demand}

About one tenth of gold demand is attributed to its technological use. As has been discussed above, gold is valuable due to a combination of superior physical and chemical properties, and its excellent electronic performance has realized an extensive use, including in medicine, engineering, and environmental management.

Statistics in Figure 2.2.1 show that technological use of gold was 346.5 tons in 2014, and the industry use is seen to remain at a stable level in pace with the continuous development of economy and technology. In particular, the rapid growth of fledgling industries has called for greater quantities of electronic products, which accordingly increase the industry demand for gold. Also, people's needs to purify water and air have built reliance on the use of gold. Developing economies and technologies are throwing light upon the superiority of gold over other low-cost but unstable metals. The visual relationship is vague, but the long-term relationship between the gold price and technology demand for gold should be positive. Producers' increasing needs for gold for scientific and technological purposes can lead to the gold price's going up. Unlike luxuries, scientific development bears great potential, which is expected to bring in future profit with chronic well-being.

\section{- Investment Demand}

As is commonly known, gold is a commodity with investment properties. It can be a substitute for investment tools such as stocks, bonds, and bank savings. For instance, when stock times are good, demand for gold is prone to relative decreases, while it tends to increase when USD depreciates or oil price goes up. Also, market expectations of gold price 
can lead to investment and hedging demand. Gold investment can be either in gold itself or gold-based financial instruments. Typical examples of the latter are gold futures and gold exchange trade funds (ETFs), which take gold as underlying assets and thus make it possible for investors to own gold without bearing storage costs. Notably, gold ETFs have brought hundreds of billions of capital into gold markets since its birth in 2004, and have yet been one of the most direct factors that influence gold price. Gold's hedging functions are especially conspicuous during economic recessions, making people prefer to hold value-storing gold instead of investing in currencies.

From Figure 2.2.1, we can see that investment demand has been declining in general during the recent 6 years. In particular, investment demand switched to short sales of gold in 2013 and 2014, as indicated by the negative amounts. A simultaneous trend is more investment in riskier assets such as stocks, which, from another perspective, reflects the reduction in people's risk aversion in these years.

\section{- International Reserves}

International reserves refer to assets held by central banks in order to maintain currency stability, balance international payments deficit, and cope with various emergency circumstances. The reason why gold can be treated as international reserves is its functions of currency liquidity, storage, and media of payment.

According to Figure 2.2.1, the past six years have witnessed a fundamental shift of the behavior of central banks to valuing gold. From the net sales in 2009, there were net purchases of gold, which increased by 621.6 tons in 2010 through 2014. This is partially because of central banks' uncertain expectations of international monetary systems in the future. At the same time, since gold does not easily depreciate and can serve as the guarantee of a country's economy, military funds, strategic stockpile, and insurance fees, the necessity of diversifying gold reserves is driving banks to increase gold purchases for future use. Therefore, international reserves are positively related to gold price on a chronic basis.

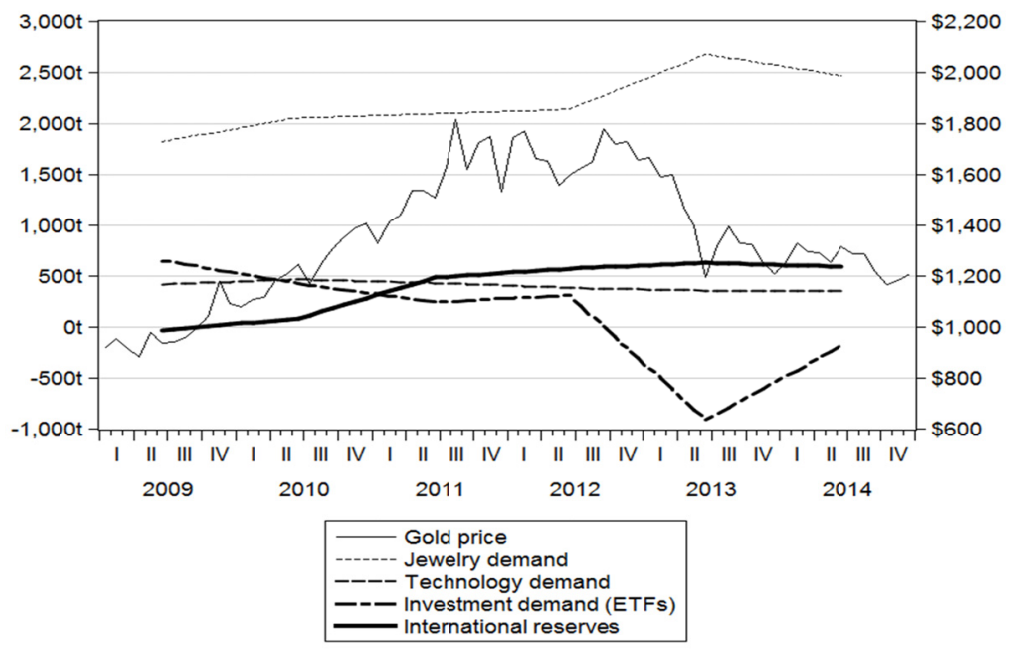

Figure 2.2.1. Gold price versus demand factors

\subsubsection{Implicit and Indirect Factors}

The supply-demand impact on gold price comes from gold's commodity properties, while gold is also characterized with currency and hedging properties. For this reason, turns in economic trends and major indicators can yield distinct levels of influence on international gold price. Since the demonetization of gold, macroeconomic indices tend to deeply affect its price, and hence it is important to analyze the implicit relationship between the gold price and various economic indicators according to the current economic situation.

\section{- Oil Price}

Oil is currently one of the most significant energy resources in the world, accounting for over one third of global energy demand. Since the Industrial Revolution, the use of oil has spread over every inch of people's life, ranging from fuel and solvent to lubricant and asphalt. In theory, an increase in oil price signifies rising industrial costs, thus leading to cost-pull inflation. Global oil price is a crucial price indicator, and so the majority of countries are sensitive to them. As for the primary oil producers, when the oil price rises, they might increase gold reserves to spread risks, which will lead to an increase in gold price. On the contrary, when the oil price falls, they tend to decrease gold demand as revenues decrease, which will result in a decline in the gold price. It can hence be known that the gold price is directly related to oil price.

Global oil price has been going up consecutively over the recent decades, increasing from $\$ 29.46 /$ barrel in May 2000 to $\$ 50.38 /$ barrel in 2015. In gold markets, increases in oil price can result in rising costs of a variety of industrial materials, 
thus leading to exorbitant inflation. At this time, gold being an inflation-protected tool, its demand and price are prone to corresponding increases.

- Stock Index

When turmoil occurs in global financial markets, the security and hedging functions of gold will come into play as prices of risky assets like stocks, funds, and bonds fall, and thus, people tend to switch to investing in gold, lifting gold price. Inversely, in stable global financial markets, investors' confidence in the future economic situation can lead to capital inflows to securities markets, and the gold price will decline as a result of decreasing gold demand. In this connection, the trend of the gold price is inversely related to that of stock price.

Among the various risky assets, stocks are in one sense the most common representative. In view of the diversity of market stock types, it is more convenient to consider stock indices, which are obtained based on selecting a group of cross-sectional stocks and calculating weighted-average prices. Further, the Standard \& Poor's 500 (S\&P500), which is an American stock market index based on the market capitalization of 500 large companies that have common stocks listed on the New York Stock Exchange (NYSE) and National Association of Securities Dealers Automated Quotations (NASDAQ) Stock Market Index, takes more diversified risks into account and can better reflect broad market turns relative to the Dow Jones, and will thus be chosen as a study object afterwards.

\section{- USD Index}

USD index is an aggregate indicator used to measure changes in USD exchange rates. It is calculated from the weighted average of 6 USD exchange rates (to the Euro (EUR), Sterling (GBP), Canadian dollar (CAD), Swiss Franc (CHF), Swedish Krona (SEK), and Japanese yen (JPY)). Rises in the USD index signify appreciation of USD and decreases in international dollar-wise commodity prices. On the contrary, the declining USD index can mean the depreciation of USD.

USD index influences the global gold price mainly from two aspects. On the one hand, since international gold is priced in USD, when the USD index goes up or down, gold price should correspondingly go down or up. On the other hand, people's investing preferences tend to change with respect to changing USD index. Based on the negative relationship between USD index and gold price trends, if USD index is expected to increase, investors will find dollar commodities more alluring, which will cause the gold price to fall; if USD index is expected to fall, investors will switch to gold market investment, lifting gold price further.

\section{- Federal Funds Rate}

Interest rate is an important financial variable, and Federal Funds Rate (FFR) is oftentimes chosen to represent the U.S. interest rate level. Changes in interest rate can influence the gold price indirectly. When the interest rate is high, its superior attractions over gold tend to lift the opportunity cost of investing in gold, and hence, increases in interest rates can result in declining gold price. On the contrary, at low levels, the interest rate is less attractive than gold, which make investors more willing to invest in gold, therefore increasing gold price.

\section{- Inflation Rate}

In economic theory, inflation is defined as a sustained increase in the general price level of goods and services in an economy during a specific period of time. Gold is thought to be one of the most effective inflation-protected tools. When inflation occurs, like other commodities, gold price tends to go up, but empirical evidence has shown a special high sensitivity of gold price to the inflation rate, which even exceeds the growth rate of inflation itself. This beyond doubt highlights the hedging function of gold, and further implies that gold price changes in the same direction with the inflation rate. The leading position of the U.S. economy in the world has led to the fact that the U.S. inflation rate can most largely affect international gold price. Besides, in pace with the their economic development, emerging nations are seeing an increasingly large impact of inflation on the spot price of gold.

\section{Quantitative Analysis}

Following the previous qualitative analysis, in this section we choose gold price, oil price, S\&P500 index (succinctly referred to as stock index), USD index, FFR and inflation rate ${ }^{(1)}$ as our modeling object, the first five obtained on a daily basis while the last on a monthly basis. For comparison purposes, we create two data sets, data set I ranging from Jan 3 , 2012 to Dec 31, 2014, with 754 daily observations and 36 monthly observations, and data set II ranging from Jul 2, 2012 to Jun 30, 2015, with 753 observations and 36 monthly observations. Both data sets will be analyzed and modeled simultaneously.

\subsection{Testing Factors Influencing Gold Price}

In the first place, we need to determine the relationship between each variable, considering the gold price as the sole dependent variable and the others as independent or explanatory variables. To begin with, we let $G_{t}, O_{t}, S_{t}, U_{t}, F_{t}$, and $I_{t}$ 
denote the series of gold price, oil price, stock index, USD index, FFR, and inflation rate, respectively, for any discrete time point $t=0,1,2, \ldots$. In particular, in order to measure $t$ uniformly in days, $I_{t}$ is assumed to be constant within a specific month.

On the purpose of shrinking the differences among the price variables, we need to take natural logarithms of $G_{t}, O_{t}, S_{t}$, and $U_{t}$ for regression analysis. No such transformations are necessary to FFR and the inflation rate in that their values are originally small. Table 3.1.1 below gives the variables' correlation matrix for each data set.

Table 3.1.1. Correlation matrices of variables

\begin{tabular}{|c|c|c|c|c|c|c|}
\hline \multicolumn{7}{|c|}{ Data set I } \\
\hline $\ln G_{t}$ & $\ln G_{t}$ & $\begin{array}{l}\ln O_{t} \\
0.106363\end{array}$ & $\begin{array}{l}\ln S_{t} \\
-0.907949\end{array}$ & $\begin{array}{l}\ln U_{t} \\
0.283830\end{array}$ & $\begin{array}{l}F_{t} \\
0.736882\end{array}$ & $\begin{array}{l}I_{t} \\
0.475904\end{array}$ \\
\hline $\ln O_{t}$ & 0.106363 & 1 & -0.120797 & 0.417838 & -0.315159 & 0.434297 \\
\hline $\ln S_{t}$ & -0.907949 & -0.120797 & 1 & -0.376483 & -0.674523 & -0.425583 \\
\hline $\ln U_{t}$ & 0.283830 & 0.417838 & -0.376483 & 1 & -0.124509 & 0.628781 \\
\hline$F_{t}$ & 0.736882 & -0.315159 & -0.674523 & -0.124509 & 1 & 0.083215 \\
\hline$I_{t}$ & 0.475904 & 0.434297 & -0.425583 & 0.628781 & 0.083215 & 1 \\
\hline \multicolumn{7}{|c|}{ Data set II } \\
\hline $\ln G_{t}$ & $\ln G_{t}$ & $\begin{array}{l}\ln O_{t} \\
0.379435\end{array}$ & $\begin{array}{l}\ln S_{t} \\
-0.912514\end{array}$ & $\begin{array}{l}\ln U_{t} \\
-0.536278\end{array}$ & $\begin{array}{l}F_{t} \\
0.663964\end{array}$ & $\begin{array}{c}I_{t} \\
0.489874\end{array}$ \\
\hline $\ln O_{t}$ & 0.379435 & 1 & -0.501754 & -0.926503 & -0.256399 & 0.861826 \\
\hline $\ln S_{t}$ & -0.912514 & -0.501754 & 1 & 0.612798 & -0.533938 & -0.538046 \\
\hline $\ln U_{t}$ & -0.536278 & -0.926503 & 0.612798 & 1 & 0.109331 & -0.880144 \\
\hline$F_{t}$ & 0.663964 & -0.256399 & -0.533938 & 0.109331 & 1 & -0.058777 \\
\hline$I_{t}$ & 0.489874 & 0.861826 & -0.538046 & -0.880144 & -0.058777 & 1 \\
\hline
\end{tabular}

Through these coefficients we can observe that, in both data sets, gold price is inversely related to S\&P500 and USD index. The correlations with oil price and inflation rate are, on the contrary, positive. Notice that there exists a direct relationship between the gold price and FFR, which is not consistent with the previous macroeconomic analysis. An explanation is that the time horizon in which the data are collected may not be long or proper enough to reflect a negative impact. Besides, there also exist correlations among the independent variables, and, in particular, both stock index and USD index are strongly correlated with FFR. These are to be taken into account in establishing our regression model later.

Figure 3.1 shows, for both data sets, the multiple scatter plots ${ }^{(2)}$ of $\ln G_{t}$ with respect to each log-price series and rate series.
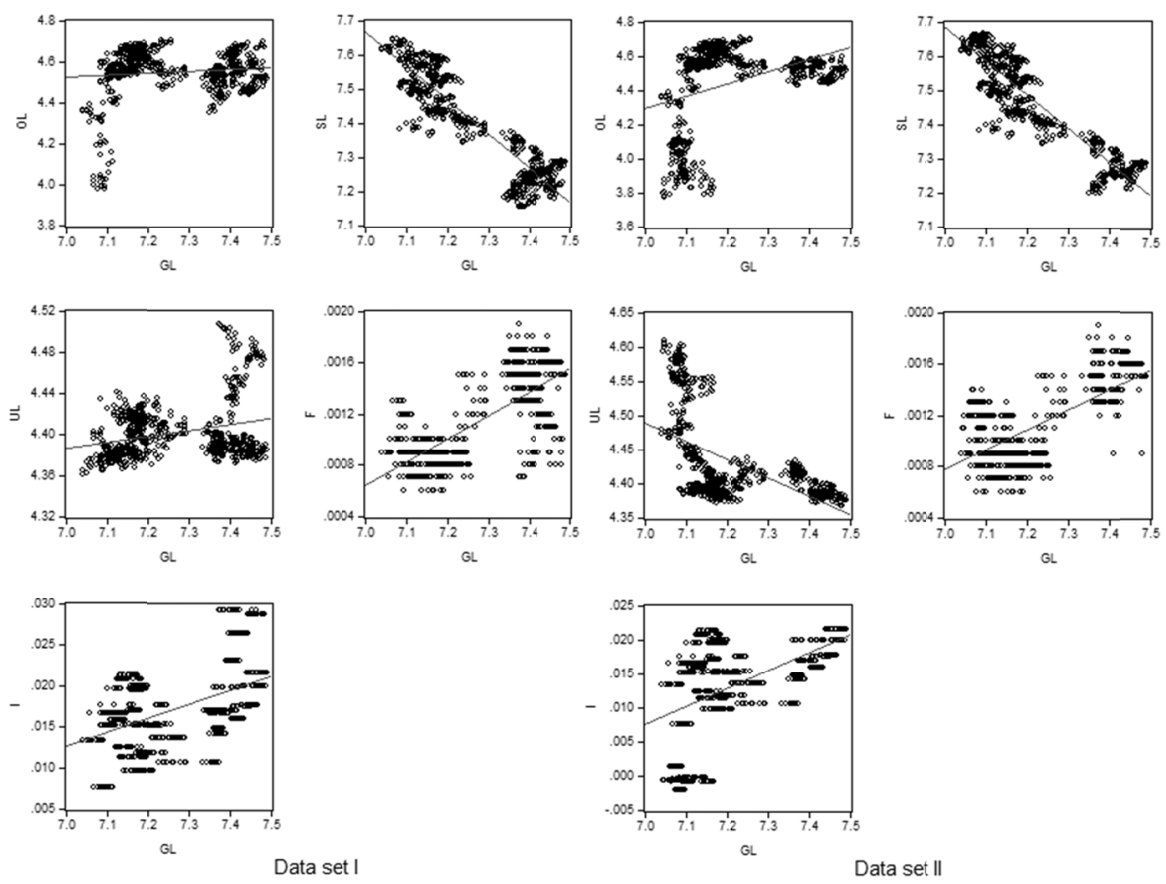

Figure 3.1. Scatter plots for variables

These plots have indicated the likelihood of linear relationships among $\ln G_{t}$ and the other independent variables. Thus, we establish a multiple linear regression (MLR) $\operatorname{model}^{(3)}$ as defined below, which applies to both data sets. Notably, values of $F_{t}$ are multiplied by 100 so that the coefficients $\left\{c_{n}\right\}_{n=0,1, \ldots, 5}$ may tend to the same level. 


$$
\ln G_{t}=c_{0}+c_{1} \ln O_{t}+c_{2} \ln S_{t}+c_{3} \ln U_{t}+100 c_{4} F_{t}+c_{5} I_{t}, \quad t \geq 0
$$

After proper variable selection, the following table presents the final MLR results for both data sets.

Table 3.1.2. MLR modeling results (daily basis)

\begin{tabular}{|c|c|c|c|}
\hline \multicolumn{4}{|c|}{ Data set I } \\
\hline $\begin{array}{c}\text { Coefficient } \\
\text { estimates } \\
\mathrm{R}^{2}=0.882993\end{array}$ & $\begin{array}{c}c_{0}=12.415330 \\
(0.0000) \\
c_{3}=-0.325325 \\
(0.0002) \\
\text { Adi. } \mathrm{R}^{2}=0.882211\end{array}$ & $\begin{array}{c}c_{1}=0.080788 \\
(0.0000) \\
c_{4}=1.222250 \\
(0.0000) \\
\mathrm{AIC}=-3.340442\end{array}$ & $\begin{array}{c}c_{2}=-0.582637 \\
(0.0000) \\
c_{5}=5.294703 \\
(0.0000) \\
\mathrm{SC}=-3.303636\end{array}$ \\
\hline \multicolumn{4}{|c|}{ Data set II } \\
\hline $\begin{array}{l}\text { Coefficient } \\
\text { estimates }\end{array}$ & $\begin{array}{c}c_{0}=14.623781 \\
(0.0000) \\
c_{3}=-0.687899 \\
(0.0000) \\
\text { Adj. } \mathrm{R}^{2}=0.900255\end{array}$ & $\begin{array}{c}c_{1}=-0.109509 \\
(0.0000) \\
c_{4}=1.449561 \\
(0.0000) \\
\mathrm{AIC}=-3.564068\end{array}$ & $\begin{aligned} c_{2}= & -0.542144 \\
& (0.0000) \\
c_{5} & =1.276734 \\
& (0.0085) \\
\mathrm{SC} & =-3.527223\end{aligned}$ \\
\hline
\end{tabular}

These results show that all coefficients are significant at the $5 \%$ level (as enclosed in parentheses, p-values $<5 \%$ ), which means that there exist strong relationships between log gold price and the independent variables. Also, the (adjusted) $\mathrm{R}^{2}$ values are quite close to 1 , indicating a high level of fitting degree.

The model specifications also give the relationship directions between the dependent variable and independent variables. Notice that the natural logarithm function is positive and monotonically increasing on the positive half real line. Thus, consistent with our explanations on the factors' impact before, stock index and USD index are inversely related to the gold price. Besides, both FFR and inflation rate positively influence gold price.

\subsection{Time Series Modeling for Independent Variables}

In this section, we will create time series models for each of the independent variables in order to respectively forecast their future values in both data sets. This modeling process, as was specified in Tsay (2005), will yield a total of five sub-models, which, in proper order, apply to oil price, stock index, USD index, FFR, and inflation rate.

Based on unit root tests, the series of $O_{t}, S_{t}, U_{t}$, and $F_{t}$ are all non-stationary, and so logarithm difference is needed for the first three and simple difference is taken for $F_{t}$; as for the inflation rate series $I_{t}$, in data set I it is stationary but in data set II it is not, and hence simple difference is taken for data set II only. The transformed series, namely oil price log-returns, stock index log-returns, USD index log-returns, FFR increments, and inflation rate increments, are specified for $t=1,2, \ldots$ as follows,

$$
\begin{aligned}
r_{t}^{(O)} & :=\ln O_{t}-\ln O_{t-1} \\
r_{t}^{(S)} & :=\ln S_{t}-\ln S_{t-1} \\
r_{t}^{(U)} & :=\ln U_{t}-\ln U_{t-1} \\
\Delta F_{t} & :=F_{t}-F_{t-1} \\
\Delta I_{t} & :=I_{t}-I_{t-1}
\end{aligned}
$$

where note that, as a forecasting approach, $t$ is measured in months for inflation rate while days for the others. By convention, we will use autoregressive moving average with positive integer-valued lags $p$ and $q$, i.e., $\operatorname{ARMA}(p, q)$ processes, to do the modeling. Suppose that $Y_{t}=\left\{r_{t}^{(o)}, r_{t}^{(S)}, r_{t}^{(U)}, \Delta F_{t}, I_{t}, \Delta I_{t}\right\}$ represents any of the transformed series, and then

$$
Y_{t}=\omega+\sum_{i=1}^{p} \phi_{i} Y_{t-i}+\varepsilon_{t}+\sum_{i=1}^{q} \theta_{i} \varepsilon_{t-i}, \quad t \geq p \vee q
$$

where $\omega$ is the intercept coefficient, $\left\{\phi_{i}\right\}_{i=1,2, \ldots, p}$ is the sequence of autoregressive coefficients, and $\left\{\theta_{i}\right\}_{i=1,2, \ldots, q}$ is the sequence of moving average coefficients for the corresponding residual series $\varepsilon_{t}$.

In the context of daily data, the lags $p$ and $q$ are expected to be no larger than 21 , assuming there are 21 trading days within a month and, for a 3-year time horizon, the data periodicity occurs at most in a monthly cycle. On the other hand, for monthly data, $p$ and $q$ are restricted not to exceed 12, or the number of months per year. In practice, the lags $p$ and $q$ are chosen according to correlograms, which are totally different for different series and data. Tables 3.2.1 through 3.2.5 present, correspondingly, the optimal model for each of the transformed time series. To be clear, our evaluation is primarily based on the Akaike Information Criterion (AIC) and Schwarts Criterion (SC), which are considered as important indicators of the relative quality of the ARMA model with the least value preferred. Apart from this, $\mathrm{R}^{2}$ values are also included to show fitting degrees. 
Table 3.2.1. Modeling results for $r_{t}^{(O)}$ (daily basis)

\begin{tabular}{|c|c|c|c|c|}
\hline \multicolumn{5}{|c|}{ Data set I } \\
\hline $\begin{array}{l}\text { Coefficient } \\
\text { estimates }\end{array}$ & $\begin{array}{c}\omega=-0.000856 \\
(0.1169)\end{array}$ & $\begin{array}{c}\phi_{1}=-0.089636 \\
(0.0032)\end{array}$ & $\begin{array}{c}\phi_{2}=-0.605847 \\
(0.0000)\end{array}$ & $\begin{array}{c}\theta_{2}=0.725139 \\
(0.0000)\end{array}$ \\
\hline $\mathrm{R}^{2}=0.037597$ & Adj. $\mathrm{R}^{2}=0.033732$ & $\mathrm{AIC}=-5.597672$ & $\mathrm{SC}=-5.573058$ & \\
\hline \multicolumn{5}{|c|}{ Data set II } \\
\hline \multirow{6}{*}{$\begin{array}{l}\text { Coefficient } \\
\text { estimates }\end{array}$} & $\phi_{1}=0.348281$ & $\phi_{2}=0.043029$ & $\phi_{14}=-0.073739$ & $\phi_{16}=-0.386578$ \\
\hline & $\phi_{17}=0.359007$ & $\phi_{19}=0.429677$ & $\theta_{1}=-0.459365$ & $\theta_{6}=0.061531$ \\
\hline & $(0.0000)$ & $(0.0000)$ & $(0.0000)$ & $(0.0001)$ \\
\hline & $\theta_{9}=0.084068$ & $\theta_{13}=0.081992$ & $\theta_{16}=0.453243$ & $\theta_{17}=-0.409848$ \\
\hline & $(0.0000)$ & $(0.0000)$ & $(0.0000)$ & $(0.0000)$ \\
\hline & $\theta_{19}=-0.519477$ & $\theta_{20}=0.179761$ & & \\
\hline $\mathrm{R}^{2}=0.101493$ & $\begin{array}{c}(0.0000) \\
\text { Adj. } \mathrm{R}^{2}=0.085247\end{array}$ & $\begin{array}{c}(0.0000) \\
\mathrm{AIC}=-5.271418\end{array}$ & $\mathrm{SC}=-5.183615$ & \\
\hline
\end{tabular}

Table 3.2.2. Modeling results for $r_{t}^{(S)}$ (daily basis)

\begin{tabular}{|c|c|c|c|c|}
\hline \multicolumn{5}{|c|}{ Data set I } \\
\hline $\begin{array}{l}\text { Coefficient } \\
\text { estimates }\end{array}$ & $\begin{array}{c}\omega=0.000579 \\
(0.0147)\end{array}$ & $\begin{array}{c}\phi_{5}=0.686775 \\
(0.0001)\end{array}$ & $\begin{array}{c}\theta_{5}=-0.731234 \\
(0.0000)\end{array}$ & \\
\hline $\mathrm{R}^{2}=0.009484$ & Adj. $\mathrm{R}^{2}=0.006825$ & $\mathrm{AIC}=-6.976507$ & $\mathrm{SC}=-6.957988$ & \\
\hline \multicolumn{5}{|c|}{ Data set II } \\
\hline & $\omega=0.000576$ & $\phi_{4}=-1.617453$ & $\phi_{8}=-0.949282$ & $\phi_{16}=0.022019$ \\
\hline Coefficient & $(0.0290)$ & $(0.0000)$ & $(0.0000)$ & $(0.2447)$ \\
\hline estimates & $\theta_{4}=1.591178$ & $\theta_{8}=0.944016$ & $\theta_{15}=0.022602$ & \\
\hline $\mathrm{R}^{2}=0.047060$ & Adj. $R^{2}=0.039217$ & $\mathrm{AIC}=-7.043911$ & $\begin{array}{c}(0.0004) \\
\mathrm{SC}=-7.000149\end{array}$ & \\
\hline
\end{tabular}

Table 3.2.3. Modeling results for $r_{t}^{(U)}$ (daily basis)

\begin{tabular}{|c|c|c|c|c|}
\hline \multicolumn{5}{|c|}{ Data set I } \\
\hline $\begin{array}{l}\text { Coefficient } \\
\text { estimates }\end{array}$ & 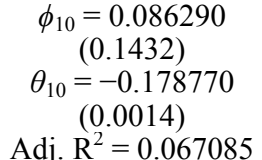 & $\begin{array}{c}\phi_{14}=-0.087360 \\
(0.0012) \\
\theta_{15}=-0.061522 \\
(0.0065) \\
\text { AIC }=-8.311522\end{array}$ & $\begin{aligned} \phi_{21} & =0.653722 \\
& (0.0000) \\
\theta_{21} & =-0.676031 \\
& (0.0000) \\
\mathrm{SC} & =-8.267573\end{aligned}$ & $\begin{array}{c}\theta_{1}=-0.083673 \\
(0.0004)\end{array}$ \\
\hline \multicolumn{5}{|c|}{ Data set II } \\
\hline $\begin{array}{l}\text { Coefficient } \\
\text { estimates }\end{array}$ & $\begin{array}{c}\omega=0.000266 \\
(0.1114) \\
\phi_{10}=0.538127 \\
(0.0000) \\
\theta_{10}=-0.658701 \\
\text { Adj. } \mathrm{R}^{2}=0.049948\end{array}$ & $\begin{array}{c}\phi_{1}=-0.230361 \\
(0.0000) \\
\phi_{11}=0.083433 \\
(0.0164)\end{array}$ & $\begin{array}{c}\phi_{2}=0.052760 \\
(0.0516) \\
\theta_{1}=0.216363 \\
(0.0000)\end{array}$ & $\begin{aligned} \phi_{7} & =0.320110 \\
& (0.0000) \\
\theta_{7}= & -0.317500 \\
& (0.0000)\end{aligned}$ \\
\hline
\end{tabular}

Table 3.2.4. Modeling results for $\Delta F_{t}$ (daily basis)

\begin{tabular}{|c|c|c|c|c|}
\hline \multicolumn{5}{|c|}{ Data set I } \\
\hline $\begin{array}{c}\begin{array}{c}\text { Coefficient } \\
\text { estimates }\end{array} \\
\mathrm{R}^{2}=0.225054\end{array}$ & 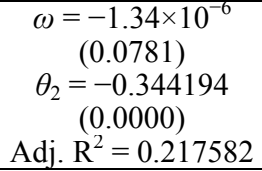 & $\begin{array}{c}\phi_{1}=-0.491678 \\
(0.0000) \\
\theta_{12}=-0.039471 \\
(0.0072) \\
\mathrm{AIC}=-15.70156\end{array}$ & $\begin{aligned} \phi_{18} & =0.791036 \\
& (0.0000) \\
\theta_{18} & =-0.900673 \\
& (0.0000) \\
\mathrm{SC}= & =-15.65144\end{aligned}$ & $\begin{array}{c}\phi_{19}=0.400663 \\
(0.0000) \\
\theta_{20}=0.318888 \\
(0.0000)\end{array}$ \\
\hline \multicolumn{5}{|c|}{ Data set II } \\
\hline $\begin{array}{l}\text { Coefficient } \\
\text { estimates }\end{array}$ & 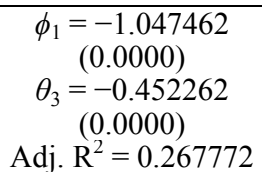 & $\begin{array}{c}\phi_{2}=-0.681161 \\
(0.0000) \\
\theta_{4}=-0.660374 \\
(0.0000) \\
\mathrm{AIC}=-15.62507\end{array}$ & $\begin{array}{c}\phi_{4}=0.556145 \\
(0.0000) \\
\theta_{5}=0.300142 \\
(0.0000) \\
\mathrm{SC}=-15.58185\end{array}$ & $\begin{array}{c}\theta_{1}=0.455676 \\
(0.0000)\end{array}$ \\
\hline
\end{tabular}

Table 3.2.5. Modeling results for $I_{t}$ in data set I and $\Delta I_{t}$ in data set II (monthly basis)

\begin{tabular}{|c|c|c|c|c|}
\hline \multicolumn{5}{|c|}{ Data set I } \\
\hline $\begin{array}{l}\text { Coefficient } \\
\text { estimates }\end{array}$ & $\begin{array}{c}\omega=0.015668 \\
(0.0000) \\
\theta_{2}=-0.359589 \\
(0.1295)\end{array}$ & $\begin{array}{c}\phi_{1}=1.254918 \\
(0.0000)\end{array}$ & $\begin{array}{c}\phi_{2}=-0.438884 \\
(0.0291)\end{array}$ & $\begin{array}{c}\theta_{1}=-0.559743 \\
(0.0274)\end{array}$ \\
\hline $\mathrm{R}^{2}=0.613432$ & Adj. $\mathrm{R}^{2}=0.560112$ & $\mathrm{AIC}=-8.891435$ & $\mathrm{SC}=-8.666971$ & \\
\hline \multicolumn{5}{|c|}{ Data set II } \\
\hline $\begin{array}{l}\text { Coefficient } \\
\text { estimates }\end{array}$ & $\begin{array}{c}\omega=-0.000416 \\
(0.0541) \\
\theta_{8}=-0.876215 \\
(0.0000)\end{array}$ & $\begin{array}{c}\phi_{8}=-0.679899 \\
(0.0052)\end{array}$ & $\begin{array}{c}\phi_{10}=-0.247897 \\
(0.1867)\end{array}$ & $\begin{array}{c}\phi_{12}=-0.287448 \\
(0.1142)\end{array}$ \\
\hline $\mathrm{R}^{2}=0.785167$ & Adj. $R^{2}=0.737427$ & $\mathrm{AIC}=-9.797301$ & $\mathrm{SC}=-9.550454$ & \\
\hline
\end{tabular}




\subsection{Forecasting the Price of Gold}

Now, it is time to give corresponding forecasts for the level of the influencing factors based on the well-established ARMA models, and load them into the MLR equation to eventually forecast the spot price of gold. The forecasting method is dynamically recursive and can be done via the following formula.

$$
\hat{G}_{t+1} \approx \exp \left(c_{0}+c_{1}\left(\ln O_{t}+\hat{r}_{t+1}^{(o)}\right)+c_{2}\left(\ln S_{t}+\hat{r}_{t+1}^{(S)}\right)+c_{3}\left(\ln U_{t}+\hat{r}_{t+1}^{(U)}\right)+100 c_{4}\left(F_{t}+\Delta \hat{F}_{t+1}\right)+c_{5} \hat{I}_{t+1}\right)
$$

where, for data set II,

$$
\hat{I}_{t+1}=I_{t}+\Delta \hat{I}_{t+1}
$$

Due to large volatility in the stock market, long-term forecast can be understandably inaccurate. For this reason we will only give the gold price forecasts 10 trading days ahead in 2015 - from Jan 2 to 15 for data set I and from Jul 1 to 14 for data set II. The absolute error between the actual gold price and the forecasts are also shown.
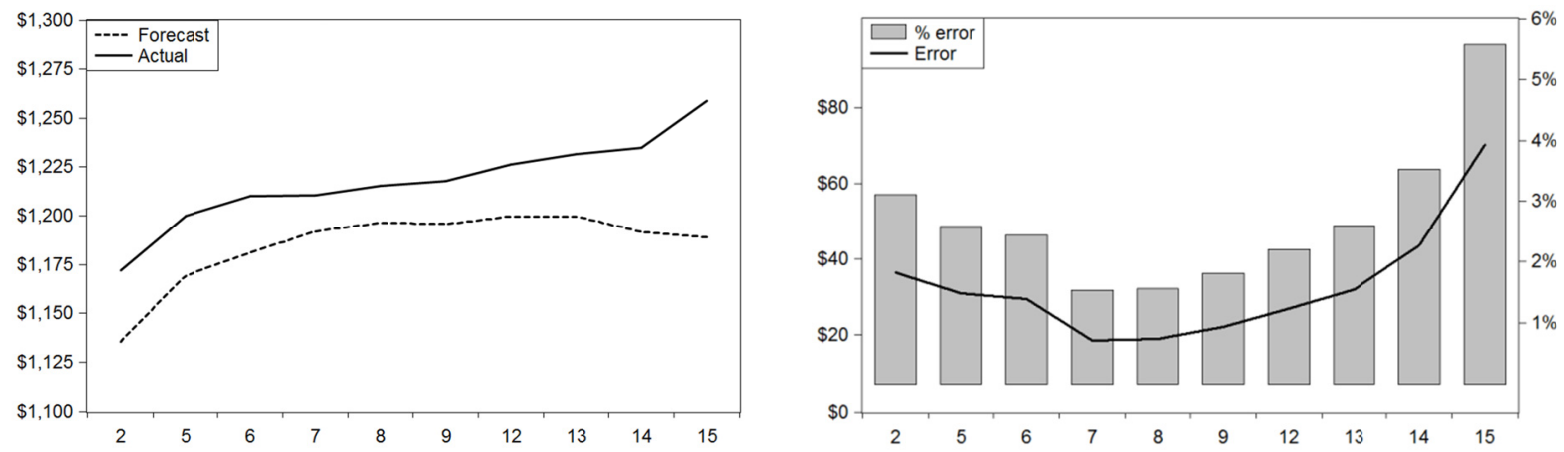

Figure 3.3.1. Gold price forecast evaluation for data set I
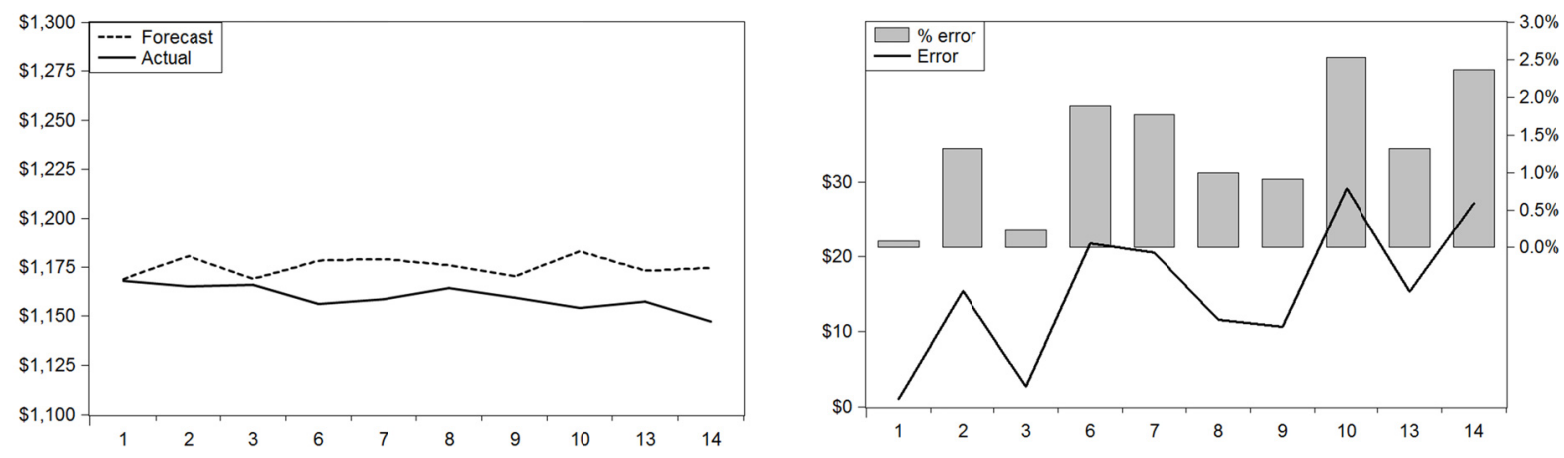

Figure 3.3.2. Gold price forecast evaluation for data set II

Seen from Figure 3.3.1 for data set I, the actual spot price of gold appears to be ascending in general over the first 10 trading days in Jan 2015 , rising approximately from $\$ 1,172$ to $\$ 1,259$. The corresponding forecasts present an approximately concave upward-sloping trend. In comparison, the two curves seem to be moving in the same direction. Deviation indeed exists, but is relatively small on Jan 7 through 9. On the other hand, in Figure 3.3.2 for data set II, trends of the forecast series and actual spot price of gold both seem quite ambiguous. However, this time the absolute error turns out to be much smaller. In particular, on the first day of the forecast, the implied gold price only deviates from the actual price by a negligible $\$ 0.94$, or $0.08 \%$ equivalently; the error remains at a considerably low level up to Jul 9. In all, these results have confirmed the significant impact of the five selected indirect economic factors on gold price, as well as reflected that our modeling structure can, to some extent, simulate the trend of short-term gold price accurately.

\section{Results and Discussion}

Motivated by the particular and significant role of gold in human society and economy and its extensive use over diverse fields, in this paper, we focus on analyzing the factors that influence the spot price of gold either in the short or the long run, and seek to forecast short-term gold price based on selected macroeconomic factors.

In the qualitative analysis we bifurcate the factors with respect to supply and demand. Generally speaking, gold supply mainly comes from four aspects, namely gold mine production, recycled gold, central bank gold sales, and producer net hedging. On a chronic basis, except that central bank gold sales negatively impact gold price, the other three factors are all positive. Also, the source of gold demand can be divided into four sectors, including jewelry, technology, investing and hedging, and international reserves. The latter three are all directly related to gold price, while jewelry demand 
places a negative impact. Furthermore, from the perspective of macroeconomic indicators, international oil price, stock index, USD index, interest rate, and inflation rate can largely affect gold price fluctuations.

In the quantitative analysis focused on these five macroeconomic variables, results of the multiple linear regression clearly reflect their implicit relations with the gold price. Generally speaking, the signs of the coefficient estimates have fit into our qualitative analysis, as a coefficient that is larger than 0 indicates a positive relationship while one that is below 0 implies a negative relationship. Increases in oil price and inflation rates tend to increase gold price, which decreases in line with decreasing stock index (S\&P500) and USD index, however. Notably, there is a misfit when it comes to FFR, but, as aforementioned, the reason is that interest rate changes during the 3-year period are insufficient to reveal a significant impact on the gold price, which can also be ascribed to the relatively weak influence of interest rate. Even so, we have still included it in our regression model due to its positive contribution to the overall fitting degree. The time series models for these five macroeconomic variables are selected comprehensively based on autocorrelation and partial autocorrelation lags together with AIC and SC values. When the independent variables' forecasts are brought into the MLR equation, the implied gold price values appear quite close to the actual price data, which guarantees the quality of our model set, and, in the meantime, indirectly confirms the relative significance of the influencing factors selected. In other words, the idea of combining a regression model that represents the impact with several time series sub-models that give forecasts can be applied to predicting short-term gold price, which usually presents inconspicuous or fickle relations with a historical gold price.

Concluded from this result, if countries can take action to control interest rate and inflation level, an indirect change in the price of gold can be realized. When the gold price is deemed to be excessively high or low, governments can also seek to correspondingly implement regulations on the stock and crude oil markets, which are expected to affect the gold price in turn. From the perspective of investors, with appropriate use of the five indirect factors as indicators of gold price trends under a real-time monitoring system, or a dynamic MLR-time-series modeling system, they will be able to gain more understanding of the structure of gold price, and thus spot extra opportunities of profit while protecting themselves against certain financial risks.

Nonetheless, the indirect macroeconomic factors chosen in this paper may be far from completeness, and many, such as political factors, are unlikely to be quantified or even numbered. On the other hand, due to existing limitations of data resources, the inflation rate has failed to be obtained on a daily basis, which inevitably affect the consistency of data types. To this point, it should be of great interest to consider additional factors that implicitly affect the spot price of gold and, if possible, refine the data frequency in order for the modeling to be more accurate.

\section{References}

Adrangi, B., Chatrath, A., \& Raffiee, K. (2003). Economic Activity, Inflation, and Hedging: The Case of Gold and Silver Investments. The Journal of Wealth Management, 6(2), 66-77. https://doi.org/10.3905/jwm.2003.320482

Gokmenoglu, K. K., \& Fazlollahi, N. (2015). The Interactions among Gold, Oil, and Stock Market: Evidence from S\&P500. Procedia Economics and Finance, 25, 478-488. https://doi.org/10.1016/S2212-5671(15)00760-1

Hewitt, A., Keel, T., Tauber M., \& Fiedler, T. (2015). The Ups and Downs of Gold Recycling. The World Gold Council $\&$ the Boston Consulting Group.

Levin, E. J., \& Wright, R. E. (2006). Short-run and Long-run Determinants of the Price of Gold. The World Gold Council, 32 .

Orlov, M. L. (1996). Multiple Linear Regression Analysis Using Microsoft Excel. Department of Chemistry, Oregon State University.

Pulvermacher, K. (2004). Gold and Hedge Funds: A Comparative Analysis. The World Gold Council, June.

Ranson, D. (2005). Why Gold, not Oil, Is the Superior Predictor of Inflation. Gold Report, World Gold Council, November.

Ranson, D., \& Wainwright, H. C. (2005). Inflation Protection: Why Gold Works Better than "Linkers". London, World Gold Council.

Sjaastad, L. A. (2008). The Price of Gold and the Exchange Rates: Once again. Resources Policy, 33(2), 118-124. https://doi.org/10.1016/j.resourpol.2007.10.002

Sjaastad, L. A., \& Scacciavillani, F. (1996). The Price of Gold and the Exchange Rates. Journal of International Money and Finance, 15, 879-897. https://doi.org/10.1016/S0261-5606(96)00045-9

Smith, G. (2001). The Price of Gold and Stock Price Indices for the United States. The World Gold Council, 8, 1-16.

Tsay, R. S. (2005). Analysis of Financial Time Series, $2^{\text {nd }}$ Ed. New Jersey, Wiley-Interscience. https://doi.org/10.1002/0471746193 


\section{Notes}

(1) Gold price, FFR, and inflation rate data are collected from Ycharts, oil price data are collected from U.S. Energy Information Administration, S\&P500 index data are collected from Yahoo Finance, and USD index data are collected from Hexun.

(2) In a convenient way, the notations "GL", "OL", "SL", "UL", "F", and "I" are used to refer to the series $\ln G_{t}, \ln O_{t}, \ln$ $S_{t}, \ln U_{t}, F_{t}$, and $I_{t}$, respectively.

(3) While Orlov (1996) discussed MLR modeling using Microsoft Excel, statistical results in this paper are mainly obtained through Eviews 7.2.

\section{Copyrights}

Copyright for this article is retained by the author(s), with first publication rights granted to the journal.

This is an open-access article distributed under the terms and conditions of the Creative Commons Attribution license which permits unrestricted use, distribution, and reproduction in any medium, provided the original work is properly cited. 